\title{
H2O-CC Combination of Reverse-Osmosis and Photovoltaic
}

\author{
Röttgers Nina ${ }^{1}$, Wefringhaus Eckard ${ }^{2}$, Link Thomas ${ }^{3}$, Gudopp Daniel ${ }^{4}$ \\ ${ }^{1}$ DELTA Umwelt-Technik GmbH \\ Rheinstraße 17, 14513 Teltow, Germany \\ Nina.roettgers@delta-umwelt.com; eckard.wefringhaus@isc-konstanz.de \\ ${ }^{2}$ ISC Konstanz \\ Rudolf-Diesel-Str. 15, 78467 Konstanz, Germany \\ ${ }^{3}$ SI Module GmbH \\ Boetzinger Str. 21 c, 79111 Freiburg, Germany \\ thomas.link@si-module.com \\ ${ }^{4}$ Deea Solutions $\mathrm{GmbH}$ \\ Kennedyallee 93, 60596 Frankfurt am Main, Germany \\ d.gudopp@deea-solutions.com
}

\section{Extended Absract}

Worldwide production and installation of photovoltaic (PV) systems has more than tripled since 2011 [1]. Along with the global trend, also installations in the MENA region increased. In these areas, about 4\% of energy is used for the desalination of seawater to meet the drinking water demands [2]. The $\mathrm{H} 2 \mathrm{O}-\mathrm{CC}$ project combines the idea of desalination by renewable energies and optimizing PV efficiency and is conducted as a collaboration between solar energy and water treatment specialists (ISC Konstanz, deea solutions GmbH, SI Module GmbH and DELTA Umwelt-Technik GmbH), funded under the KMU-innovative program. A reverse-osmosis (RO) plant with a capacity of $1 \mathrm{~m}^{3} / \mathrm{h}$, connected to solar energy is installed in El Gouna, Egypt. As feed-water source, a beach well is used, which provides salinity close to the one in the red sea (about $42.000 \mathrm{ppm}$ ). The set-up includes ultra-filtration pre-treatment and three pressure vessels for the reverseosmosis modules which can be used independent of each other. This design allows to adjust the water production between 20 and $100 \%$ regarding the full system capacity, allowing to increase and decrease water production depending on the available energy. The system is constructed as an island solution with an added option of grid connection and water production follows the energy yield. An adjustment to regional specifications such as lower salt content in the feed water can easily be conducted. For the pilot plant, solar energy is provided by 12 high efficient (60 cell-PERC) PV modules and buffered by a battery system. The main challenges here are the transformation of power, so it can be used by the RO plant and the prevention of sudden pressure drop/increase in the RO system.

Another aspect of the project is the optimization of PV module performance. Prior studies demonstrated a decrease in efficiency of the PV modules due to sand depositions on the surface [3]. To minimize this effect, a flushing system which uses some of the water produced by the RO is installed. The water flow along the front of the module reduces the temperature and the reflection of the modules at the same time [4]. Experiments at ISC Konstanz showed a significant enhancement of daily power output of $15 \%$ if a thin water layer is constantly applied. The main challenges of this part of the project are to select suitable module materials (glasses, encapsulant, backsheet) which withstand persistent dampness, to determine how much the different but correlated effects (cleaning, cooling and antireflection) contribute, and to balance the positive effects with costs due to provision, pumping and evaporation of water.

\section{References}

[1] ISE Fraunhofer, Photovoltaics $2017 . \quad$ Report, Online]. Available: https://www.ise.fraunhofer.de/content/dam/ise/de/documents/publications/studies/Photovoltaics-Report.pdf

[2] Clean Energy Business Council, Water and Energy in MENA. Challenges, Opportunities and Potential, 2014. [Online]. Available: http://www.cleanenergybusinesscouncil.com/site/resources/files/Energy-and-Water-inMENA.pdf 
[3] M. E. Maghami, et al, "Power loss due to soiling on solar panel. A review," Renewable and Sustainable Energy Reviews, vol. 59, pp. 1307-1316, 2016.

[4] S. Krauter, "Increased electrical yield via water flow over the front of photovoltaic panels," Solar Energy Materials \& Solar Cells, vol. 82, pp. 131-137, 2004. 